\title{
La experiencia de Dios
}

\author{
Dean Brackley, \\ Centro de Reflexión Teológica, \\ San Salvador, El Salvador.
}

Hay seres humanos que afiman haber encontrado a Dios o, como dice la Biblia, haberlo "conocido", y esto ha ocurrido bajo condiciones diversas a lo largo de la historia. Así, los historiadores de las religiones suelen ubicar la experiencia de Dios de las sociedades tradicionales en el encuentro con la naturaleza incontrolable, mientras que en el mundo moderno la ubican en el misterio de la conciencia humana. Por su parte, la teologla latinoamericana enfatiza el encuentro con Dios en las victimas de la injusticia y en sus luchas de liberación.

En este ensayo queremos reflexionar sobre esta experiencia de Dios en las víctimas y ver cómo puede poner en perspectiva las otras dos aproximaciones a la experiencia de Dios.

\section{La sociología de la experiencia de Dios}

A lo largo de la historia, y hasta hoy, la mayor parte de la raza humana ha sido pobre, es decir, sus vidas han sido una lucha diaria por la vida ante la amenaza permanente de la muerte. Esta ha sido la experiencia del ser humano "promedio" de todas las épocas. Ha sido y sigue siendo el drama central de la historia humana, y por eso nos parece también que constituye el lugar privilegiado del encuentro con el Dios de vida del que da testimonio la Biblia.

Sin embargo, no parece que la teologfa ha tenido siempre en cuenta y valorado debidamente este drama central de nuestra historia, lo cual, por otra parte, no debiera sorprendernos tanto, porque quizás los seres humanos, tanto pobres como no pobres, vivimos en constante olvido y huyendo de esta realidad historica de tan dura lucha y de la experiencia de Dios. Por eso, queremos comenzar recordando un dato fundamental: a lo largo de la historia, la gran mayoria de los pobres humanos —quizás un 95 por ciento- ha sido campesinos pobres. 
Pues bien, la sociedad agrícola tradicional celebra la vida y sus beneficios como un gran don que viene a través de la naturaleza incontrolable. Uno se siente pequeño y dependiente ante las fuerzas naturales, fuentes de vida y también de muerte. Semejante experiencia facilita el sentido de un Dios majestuoso, creador de la naturaleza y providente históricamente. Facilita una experiencia personal y comunal del misterio tremendum et fascinans (Rudolf Olto), que da sentido a un mundo violento y el que, sin la divinidad, carece de sentido pleno.

Esta sociedad tradicional a nivel mundial se ha visto erosionada lenta, pero irreversiblemente, en los últimos siglos de muchas formas, primero entre los países del norte en el siglo XIX, y, en el siglo actual, en las antiguas colonias pobres del sur. Si bien es cicrto que las sociedades tradicionales no han desaparecido, disminuyen cuantitativamente y su ethos queda cada vez más cuestionado cualitativamente.

Es cada vez más claro que el proceso de modemización ha causado dos cambios importantes en la siluación religiosa. Por primera vez en la historia, nuevos modos de producción han permitido el desarrollo de amplias "clases medias" que ahora viven más allá de la lucha diaria para subsistir y no lienen por qué echar de menos a un Dios providente. En segundo lugar, por su modo nuevo de pensar, más empírico y cientílico, estas nuevas clases viven en mundo desencantado y sin misterio. Al sentirse menos dependientes de una naturaleza incontrolable, se les hace menos fácil creer en un Dios creador. Cucsta creer en Dios en un mundo secularizado, y más todavía en una sociedad opulenta.

Para estas clases sociales, sin embargo, no ha desaparecido el sentido de misterio, aunque, para hablar con más precisión, habría que decir que no ha desaparecido la confusión y la inseguridad. La principal consecuencia para una teologia que surge de la modernidad es, pues, que la secularización desplaza la experiencia de misterio del mundo objetivo a la conciencia subjetiva'. Dios sigue siendo aquel que da sentido a un mundo que, sin Dios, carece de sentido pleno. Veámoslo.

La sociedad tradicional tenía una cosmovisión y una ética monolíticas, y, consecuentemente, toleraba poco todo lo que fuera hetcrodoxia. EI avance de la modernidad, en cambio, trae el pluralismo. Mi manera de componer el mundo y de entender la vida resulta ahora sólo una manera entre otras posibles. Si es cierto que comparto un mundo con familiares y vecinos, me topo también con personas que tienen visiones distintas, con ciudadanos de otros mundos que cuestionan mi propia cosmovisión. Estos otros son los que revelan el carácter relativo, parcial, limitado y hasta falso de mi mundo. De esta forma pueden llegar a deshacer mi antiguo mundo ${ }^{2} y$ hasta m: identidad.

En la sociedad tradicional, la identidad de las diversas personas quedaba 
bastante clara y estaba arraigada en roles sociales fijos. Se sabla lo que era ser varón y mujer, campesino y cocinera, partera y militar. Las personas se sentían inseguras ante la naturaleza, pero se sentran bastante seguras con su identidad de costurera, sacerdote, artesano. Eran raras las "crisis de identidad". En cambio, en la nueva sociedad pluralista uno se siente menos seguro como persona - con más posibilidades de jugar roles distintos en la sociedad, pero con roles menos fijos. Si puedo ser mecánico hoy y motorista mañana, entonces ¿cómo puedo identificarme con mi función social? ¿Qué y quién soy?

En esta situación, los portadores de cosmovisiones distintas y aun contrarias tienen la capacidad de descubrir las contradicciones de mi propia identidad, la cual está siempre mediada por mi entorno social ${ }^{3}$. Pueden arrojarnos a un abismo de confusión y desorientación -de anomia-, eco de aquella experiencia del recién nacido que tanto interes 6 a Freud, experiencia de dependencia radical y total de la madre y el padre. "Las cosas se des-integran", dice el poeta Yeats. El mundo y mi persona se deshacen.

Mientras que en la sociedad tradicional el caos amenazaba a la comunidad, en la sociedad moderna suele amenazar al individuo. Este, además, se encuentra más solo por lo general, y por ello probablemente sufre una mayor desorientación que sus antepasados.

Esta experiencia de la conciencia moderna, junto con el desencanto del mundo, sigue siendo, probablemente, el eje alrededor del cual la teología modema habla de la experiencia de Dios. La teología interpreta esta experiencia dentro del contexto fundamental del proceso de secularización (desencanto del mundo exterior) y del giro hacia el sujeto (y su mundo interior). El individuo moderno no experimenta a un Dios de un cosmos inexplicable, sino a un Dios que, en cuanto misterio, es "horizonte" del espiritu humano".

De esta forma, y quizás inconscientemente, la teología moderna tiende a considerar la secularización y la Ilustración como el eje fundamental de la evolución progresiva de la conciencia humana y de su experiencia de Dios. Y suele considerar la experiencia de las clases medias e ilustradas como paradigma y como avance - sin especiales ambigüedades - con respecto a la experiencia del pobre de ayer y de hoy. Sin duda alguna, este proceso representa avances reales, - por lo menos posibilita avanzar en la comprensión del encuentro Dios-humanidad. Sin embargo, interpretar el significado religioso de la modernidad sólo a la luz de la secularización-Ilustración conduce a una serie de errores - aun sin tener en cuenta ahora la depredación y la tiranía vinculadas a la modernización.

En primer lugar, si es cierto que la Ilustración y el desencantamiento del mundo representan un gran avance para la humanidad, la superación de la lucha diaria contra la muerte de parte de las clases medias es un fenómeno que está 
lleno de ambigüedades. El desarrollo económico de las clases medias ha sacado a éstas de la miseria, pero ha dejado atrás a las grandes mayorías. La cultura moderna, pues, trae por un lado beneficios reales que no son puros privilegios y que liberan a las personas para actividades valiosas. Pero por otro, permite ocultar la dependencia radical en que todos vivimos. Al sacar a los no pobres de la lucha diaria contra la muerte, las libertades y las oportunidades que ofrece la modernidad llevan a cierta desorientación - como una leve pero permanente calentura - acerca de lo que realmente es importante en la vida, y distancia al individuo del drama central de la historia. ¿No afectará esto negativamente su acceso al Dios de la vida?

En segundo lugar, aunque la experiencia religiosa de los pobres de la antigüedad brota ciertamente, al menos en parte, de su experiencia de un mundo natural incontrolable y encantado, fuente de vida y de muerte, este es sólo un aspecto de la experiencia más fundamental y englobante en la vida del pobre: la lucha diaria para conservar la vida ante la amenaza de la muerte. Esta lucha no es en modo alguno una etapa superada, sino que sigue siendo el pan de cada día para la gran mayoría de los miembros de la raza humana.

La modernidad ha desarraigado de sus tierras ancestrales a los pobres, y éstos se convierten, cada vez más, en pobres urbanos. Sin embargo, si muchos hombres y mujeres se han distanciado de la naturaleza como fuente inmediata de vida y muerte, y si la naluraleza ha perdido para muchos, para bien o para mal, el sentido del misterio, sus vidas siguen consistiendo en un gran drama de lucha entre la vida y la muerte. El proceso de modernización ha desencantado al mundo del pobre, pero no lo ha sacado de su dependencia radical. El mundo se ha hecho más controlable para algunos, pero no para la mayoría. Su mundo, y el don de la vida, siguen estando fuera de su control, aunque son capaces de conocer cada vez mejor las causas sociales de esta situación.

Ante la dura realidad de las inmensas mayorías de pobres, hay que preguntarse si no son éstos, más que los no pobres ilustrados, el lugar privilegiado del encuentro con Dios precisamente porque luchan diariamente en favor de la vida. Esta pregunta se impone con más fuerza si tomamos en cuenta que la amenaza diaria contra la vida no proviene en primer lugar de un mundo natural, de tal manera que la ciencia y la tecnología por sí solas puedan eliminar la pobreza. La amenaza proviene, ante todo, de un mundo social injusto. No se trata en primer lugar de un problema técnico, sino de un problema práctico y moral. La lucha por la vida y contra la muerte es un lucha entre el bien y el mal. ¿No será por eso un lugar de encuentro privilegiado con el Dios bueno que da vida y se opone al mal?

En lo que sigue, vamos a examinar primero el planteamiento de la teología moderna de la experiencia de Dios, para apreciar sus aportes valiosos y sus límiles. Y después, reflexionaremos sobre la experiencia del encuentro del no

Digitalizado por Biblioteca "P. Florentino Idoate, S.J."

Universidad Centroamericana José Simeón Cañas 
pobre con el pobre, como experiencia paradigmática del encuentro con Dios hoy.

\section{La experiencia de Dios en la teología de la modernidad}

\section{1. "Abismo".}

Los mitos de las aguas del caos primordial reflejan en la literatura antigua la experiencia de una realidad incontrolable que amenaza a nuestro cosmos ordenado, a nuestro mundo, y a la que, en la Biblia, el Creador ha podido someters. Hemos visto cómo el caos amenaza al pobre campesino de la sociedad tradicional de una forma y al no pobre moderno de otra. El pobre vive una dependencia radical y la muerte lo amenaza. Al no pobre y al individuo modemo los amenazan el sinsentido y la desorientación. (El pobre urbano de hoy vive las dos cosas a la vez, y por esto existe tanta desorientación entre los jóvenes de los sectores pobres de las ciudades.)

También el individuo moderno presiente que todo sentido-de-la-vida, toda seguridad - sea en forma de dinero, de salud, de fuerza física, de poder político, de familia, de amor humano, de amistades, de prestigio, de cosmovisión, de identidad personal o grupal, de conocimiento o sabiduría - "flota" sobre un abismo. La manera de dar forma a todo esto es frágil, y fácilmente se derrumba.

El abismo, entonces, constituye el horizonte de las actividades concretas de cada día. En la vida cotidiana nos sumergimos en los detalles que son manejables - hablamos, trabajamos, viajamos-, echando al olvido el abismo que rodea todo. Pero el abismo esı́́ ahí, y nos sale al encuentro cuando los fracasos y las crisis nos despiertan, poniendo en duda nuestras seguridades frágiles y parciales.

Así, en sus distintas formas, la experiencia del abismo nos cuestiona radicalmente el significado de la vida. Este contexto vacio de mi experiencia, ¿es hostil o es más bien amistoso? ¿Es pura Nada (Heidegger)? ¿Es el absurdo (Sartre, posmodernismo)? ¿Es puro caos?

\section{2. "Misterio"}

Partiendo de esta experiencia y de estas preguntas, la teología moderna ve en este abismo el lugar del encuentro con Dios ${ }^{6}$, y afirma que es el misterio, lo incomprensible. El misterio es lo que fundamenta y posibilita el mundo que yo he configurado, mi mundo, mi identidad.

Usando una meláfora, somos como personas que viven en un pequeño clrculo o isla de luz. Seguimos creyendo que este circulito descubierto por nuestra razón abarca todo lo que hay, pero la verdad es que un océano vasto, oscuro e incomprensible rodea la isla? ${ }^{7}$. Hay un interrogante que rodea y posibilita la isla 
de luz. Desde esa perspectiva interrogante, nuestra experiencia (personal y colectiva) tiene un horizonte, un límite abarcador. No es una cosa, un ente entre los demás entes. Es lo que rebasa todas las cosas, lo que subyace y fundamenta toda mi experiencia y la interpretación de la misma. Dios se da.

Según el mejor representante de esta teología, Karl Rahner, este misterio es precisamente el Misterio Santo que llamamos "Dios". Este misterio fundamenta mi trascendencia (la capacidad que soy de salir de mi mismo en conocimiento, en libertad y en amor), y es la meta final de mi existencia (y de la historia).

Trasciendo, sí. porque soy un dinamismo libre que conoce y que ama. Pero el Misterio Santo que posibilita esta trascendencia mía corresponde a ella también. Es parte de la condición humana experimentar siempre y en todo lugar la auto-oferta de Dios. Esta es la verdad fundamental: Dios se nos ofrece, se nos da, se comunica - a la historia por el medio concreto de Jesucristo, a mí y a la Iglesia por el medio concreto del Espíritu Santo.

El Misterio Santo me rodea —descle dentro y desde fuera. Se me acerca dentro de, y por medio de mi vida concreta, actual, por medio de los detalles cotidianos y mundanos. Me abarca, me acosa, me persigue -sin violencia pero con constancia, insistencia. Con terca fidelidad.

La salvación no es otra cosa que acoger la autodonación (gracia) de este Misterio Santo que me diviniza. Dios hace que participemos en la vida divina sin que ésta absorba al individuo, sino que lo realiza, lo personaliza, volcándolo hacia los demás.

La vida -en todos sus detalles- es el medio a través del cual Dios se me ofrece (y se me revela). Todo sirve para mediarlo, para canalizarlo. No tenemos que ir al desierto, al convento, o salir de la carne o de la historia como los gnósticos. Todo lo contrario. Dios se ofrece en todo. Aunque el mal no viene de Dios, Dios se sirve de todo, aprovecha todo - fiestas y hasta masacres- para ofrecérseme a mí, compartiendo su realidad conmigo.

Pero si es cierto que Dios accecle a nosotros por medio de la creación, Dios se nos da inmediatamente, en completa intimidad. "Dios se nos da sin intermediario. El mismo, tal y como es. sc vuelve la rcalidad más íntima de nuestro ser" (Rahner). Este universo, la historia, la vida diaria y sus detalles que sirven de sacramento no se interponen entre el Misterio Santo y nosolros. La razón de esto es que el Misterio Santo no es otro ente entre los demás. Es como agua que me llega y me empapa directamente, aunque pasando por una esponja o por olro medio.

Ante esta experiencia de Dios en el abismo nos quedan dos reacciones de fondo. Una es que anie el abismo puedo ceder a la desesperación o buscar controlar y manipular mi mundo a toda costa. Es decir, puedo rechazar la oferta e 
intentar rehuirla. Esta ha sido gran parte de la historia del mundo. La otra es que puedo reconocer en la experiencia una invilación a abandonarme al misterio incontrolable e incomprensible y reconocer que es misterio (no puedo comprenderlo), y es santo (objeto de amor libre). A este abandonarse al misterio es a lo que llamamos " $[\mathrm{e}$ ".

En la medida en que uno acepla la oferta de Dios, loda la vida se vuelve abrazo de Dios; y toda la vida se me ofrece también como "purgatorio" humanizante.

\section{La experiencia de Dios desde los pobres}

Esta manera de comprender la experiencia de Dios tiene un gran potencial. Sin embargo, queremos hacer algunas precisiones para asegurarnos de que apuntc realmente a un encuentro adecuado con el Dios de Jesús de Nazareth. Para ello, creemos que es necesario jerarquizar los lugares o mediaciones (los "sacrauncntos") de la experiencia de Dios.

Pero antes queremos complementar la imagen fructífera de horizonte (luz e isla), imagen epistemológica, con otra meláfora sugerida por lo que ya hemos dicho antes. En efecto, solemos vivir en la superficie (o periferia) del drama que es nuestra vida. Habita en nosotros una tendencia permanente a huir de la realidad, tendencia a la des-encarnación. Nos distraemos, huimos del drama más denso de nuestra realidad histórica y, en particular, de la muerte y del mal. Huimos de estas realidades en nuestro entorno, y las rehuimos dentro de nosotros también. Tenemos que huir del mal ajeno porque, como veremos, de otra forma tendríamos que asumir la verdad insoportable del mal propio. Por lo tanto, no vivimos en el centro de nosotros mismos. Nos protegemos de la dura realidad del mundo y de la hiriente realidad de nuestra muerte y nuestro pecado.

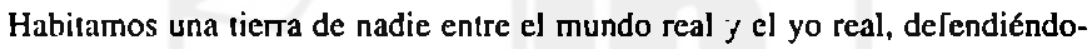
nos, con gran esfuerzo, de las ingerencias de la verdad propia y ajena. Así vivimos en un mundo ilusorio ${ }^{8}$. En la vida diaria, nos portamos, especialmente los que vivimos en la periferia, como observadores de un mundo exterior simple y unidinnensional. Pero la realidad es distinta. Revela múltiples niveles de significado como un capullo que se abre ante ojos sensibles a la belleza (aunque revela mucha fealdad rambién). Para salir del mundo ilusorio y narcisista, es necesario que la realidad misma rompa la burbuja de este mundo falso. De esta forme nos podremos encontrar ante la realidad, no la falsa realidad, sino la rcalidad rica y compleja, desafiante y Iransida de misterio.

En un primer momento, todo esto causa vértigo y no es todavia la experiencia del Misterio. Sólo cuando nos encarnamos profundamente en la misma realidad histórica - y en esa medida - nos encontramos, en un segundo momento, anle el Misterio. La realidad, que es comprensible y no opaca, está a la vez empapada del Misterio Santo. Entonces, lejos de salir de la realidad para enconDigitalizado por Biblioteca "P. Florentino Idoate, S.J."

Universidad Centroamericana José Simeón Cañas 
trar a Dios, hay que entrar plenamente en la realidad histórica y personal para encontrarlo -encarnación que, como veremos más adelante, no tiene nada que ver con un activismo sin contemplación y oración.

¿Cómo hacer, entonces, para despertar del sueño de la cotidianeidad y de la rutina? ¿Cómo hacer para introducimos más profundamente en la realidad? Si bien, en principio, toda experiencia, toda realidad que dejo que me afecte puede servir para desinstalarme de la periferia de la realidad y ponerme ante el Misterio de Dios, hay ciertas experiencias que sirven como mediaciones más poderosas que otras. Y hay que "jerarquizarlas" y "priorizarlas". La medición del abismo misterioso es y puede ser una experiencia de la belleza o del amor. Sin duda, el dolor y la tragedia de la vida pueden despertarnos del sueño. Y también la desorientación radical -que Sartre llamó la "náusea"- puede arrojarnos al abismo y ponernos ante el Misterio. Sin embargo, hay que preguntar si estas experiencias necesariamente nos ponen ante el Misterio de Dios.

Puede haber, pues, experiencia del abismo sin encuentro con Dios. Cada experiencia de Dios es parcial, limilada, por definición, y por ello algunas experiencias parciales del abismo pueden conducir a interpretaciones ununcadas que positivamente distorsionan la realidad de Dios. Por eso, hay que especificar que la mediación privilegiada para ponernos ante Dios es el prójimo. Así, en sus mejores momentos, por ejemplo, en Karl Rahner, la teología moderna ve en el encuentro con el prójimo y en el amor al prójimo el lugar de privilegio del encuentro con Dios".

Sin embargo, tampoco es suficiente hablar del projjimo sin más. Lo que me pone necesariamente ante Dios es aquel projimo que, por una parte, es otro "yo" (asi me puede dasafiar), pero que, por otra parte, es también diferente a mí: aquel que contradice mi mundo, mi identidad. Este prójimo es ante todo el pobre, la víctima de la injusticia masiva de este mundo ${ }^{10}$; es especialmente la mujer y las razas despreciadas - ambas doblemente oprimidas. El pobre tiene poder "destructor" de mi mundo parcial. Me quita toda seguridad y me pone ante la realidad histórica, tanto social como personal. El pobre me confronta no sólo con la muerte y el pecado del mundo exterior, sino que, por ser otro "yo", evoca también, desde el lugar en que las he enterrado, las verdades de mi propia muerte y pecado.

El encuentro con el pobre es experiencia de riquezas insondables. Ayuda a descubrir la riqueza multidimensional, insondable, de la realidad. Encontrarse con la víctima es como comenzar una partida de ajedrez. Como aquel cuya vida es amenazada, el pobre me pone ante el drama central de la historia. Me pone ante el Dios de la vida, porque la lucha por la vida contra la muerte es, en su realidad más profunda, lucha entre el bien y el mal, entre la gracia y el pecado, entre el Dios de la vida y los ídolos de la muerte ${ }^{11}$.

Reflexionemos ahora sobre una experiencia concreta. 


\subsection{La víctima como sacramento: un ejemplo}

Miles de personas de América del Norte y de Europa han visitado y siguen visitando los países centroamericanos durante los años terribles de conflicto. Vienen como peregrinos para compartir el via crucis de estos pueblos pobres y sufridos. Como los peregrinos de antes, se apartan de lo suyo en búsqueda de algo que da sentido a la vida. Vienen buscando esperanza, sean conscientes de esto o no, sean ateos o creyentes. Y es cierto: en estos días la gente de Centroamérica exporta más esperanza que café o banano.

Las delegaciones solidarias llegan algo ansiosas ante la novedad que les espera. Son personas generosas y quieren saber cómo pueden ayudar, si con dinero o con protestas, etc. Les decimos que la tarea principal es escuchar a la gente, que dejen que la gente les cuente sus historias ${ }^{12}$.

Los visitantes escuchan a los pobres. Estos les hablan de sus guindas, de las torturas, del hambre, de los bombardeos y de la muerte prematura. Si los visitantes tienen el valor de escuchar sus historias, la gente les parte el alma. Pero luego -ahí mismo- les regala algo más precioso.

Los visitantes ya sablan de antemano las atrocidades de las que han sido objeto. Incluso se habían preparado de alguna forma para encontrarse con la miseria. Pero pronto se preguntan por qué sonríe esta gente, pues a pesar de todo sonríen. Los visitantes no esperaban la alegría de la gente. Y ¿cómo es que esta gente quiere compartir lo poco que tiene?

La alegría y la generosidad de la gente sufrida no es toda la realidad. Esta gente tampoco es del todo santa. Hay tristeza y a veces desesperación. Pero lo que más impacta a los visitantes es la alegría y la generosidad. Y, como ellos mismos dicen, vuelven a sus países "arruinados" de por vida. Con aquellos que han compartido su dolor, el pueblo comparte también su esperanza, esperanza arraigada en un proyecto común en favor de la vida y ante la constante amenaza de la muerte. Esperanza que se expresa en alegria y generosidad, a pesar de todo. Esta alegría no parece tener causa alguna -ni el dinero, ni la salud, ni comodidad alguna. ¿De dónde o de quién puede, pues, provenir la alegría? Nos atrevemos a responder que se trata de la presencia del Resucitado en su pueblo.

\subsection{La víctima como sacramento: interpretación.}

Retlexionemos ahora más a fondo sobre encuentros como éste, que parecen iluminar también lo que está en juego en encuentros menos dramáticos. Veámoslo.

Las culturas opulentas del norte viven relativamente alejadas del gran drama central de la mayoría de la humanidad, la lucha por la vida. No es que seamos ingenuos, pues no sólo existen no pobres que son solidarios ( $y$, además, existe 
pobreza en el primer mundo), sino que, por otra parte, muchos pobres también buscan alejarse del drama, aunque les cuesta más salir de él. La gran mayoŕa, tanto de pobres como de no pobres, huimos, con los medios de que disponemos, de la muerte, el dolor y el pecado, lanto del ajeno como del propio. Y para la minoría solidaria (pobres y no pobres) huir siempre es una tentación. Todo esto sugiere que el encuentro del no pobre con el pobre puede servir bien para ilustrar, en forma dramática, cómo el pobre sirve como lugar de encuentro con Dios para todos, sean pobres o no.

La mayoría vivimos en la superficie de la realidad historica y así tratamos de prolongar la inocencia de la niñez. Los niños suelen ser ingenuos respecto al mal, pero con el tiempo, el mal y la realidad de la muerte imumpen en su vida consciente. Entierran y reentierran esta experiencia, huyendo de la crueldad de la vida y de sus víctimas.

Pero de hecho nos cuesta a todos mantener en el olvido la verdad dura del pecado y de la muerte. Los hechos implacables del sufrimiento propio y ajeno cvitan que pasemos toda la vida dormidos. El mal y la muerte forman parte de nuestras vidas, $y$, aun ausentes, se mantienen siempre en el horizonte de la experiencia e irrumpen -por ejemplo en los medios de comunicacion- con la fascinación de to reprimido. Por eso, todos vivimos con la sospecha más o menos consciente de que el mundo (y yo en particular) anda mucho peor de lo que nos atrevemos a admitir. Y es cierto. Esta sospecha tiene base sólida en la realidad. Estas malas noticias son una parte de la verdad. La otra es que las cosas también andan mejor de lo que nos atrevemos a pensar. El encuentro con la víctima tiene una capacidad única de ponernos ante esta doble verdad que nos hace libres.

Si nos dejamos locar por la violencia de la vida real del pobre, violencia lenta de la pobreza y violencia repentina de la represión y el crimen, eso nos hace detenemos en el camino y nos recoge. Pero la experiencia también nos asusta. porque los pobres pueden artojarnos al abismo de la confusión. Las víctimas de la historia pueden romper (abrir) los corazones y reventar nuestros mundos demasiado pequeños. ¿Cómo lo hacen?

La clave está en que estos seres humanos que cargan sobre sus hembros la crueldad, es decir, la verdad de este mundo, revelan nuestra identidad relacionándonos con ellos. Si dejamos que sus historias rompan las barreras que imponemos, si tenemos cl valor de ver al pobre cara a cara, comenzamos a ver ahí nuestro reflejo, no un reflejo narcisista, sino un reconocimiento de nuestra ccmún humanidad. Nos enconıramos ante la verdad de que estos pobres -a quienes los no pobres hemos considerado menos humanos- son en verdad, más allá de toda diferencia, precisamente lo que nosotros somos.

Muchos se espantan y huyen ante esta experiencia porque los lleva a perder

Digitalizado por Biblioteca "P. Florentino Idoate, S.J."

Universidad Centroamericana José Simeón Cañas 
control del mundo $\longrightarrow$, mejor dicho, a sentir que el mundo comienza a perder control sobre ellos. Pero, ¿qué mundo? Es un mundo compuesto de personas importantes, como los no pobres, y de personas sin importancia. Esta comunión en la identidad con el pobre sacude al no pobre, lo desinstala, lo hace sentir pequeño, ordinario. El mundo se des-hace. El pobre concreto, representante de las víctimas de todas las épocas, nos fuerza a reconocer el mundo en el que nos hemos socializado, mundo tan real y tan falso a la vez, como lo es un lugar de violencia espantosa contra la dignidad de las grandes mayorfas. En una palabra, los pobres nos ponen ante la realidad del pecado. Nos ponen ante el gran drama del pecado y la gracia.

Nuestra complicidad con este mundo tan desordenado nos acusa de pecado. La historia del pobre nos señala como culpables. Sin embargo, si permitimos que esta experiencia se apropie de nosotros, se nos abre dentro de ella otra dimensión sumamente rica y humanizante. Ante todo, el pobre nos invila a dejar de lado el gran peso de nuestra propia superioridad. Nos sentimos más pequeños, pero no más pequeños de lo que somos en realidad. Nos encontramos en la presencia de una hermana o hermano que ha dejado de ser inferior a nosotros.

Más importante aún es que dejemos que el pobre nos parta el alma, que podamos experimentar un dolor y vergüenza dulces, completamente distintos de la culpabilidad y el remordimiento paralizantes. Se trata de un dolor consolador y una confusión liberadora que, sorprendentemente, parecen recoger las fuerzas dispersas de la persona, haciéndola sentir entera y con dirección ${ }^{13}$. Es el dolor de la solidaridad que hace suyo el dolor ajeno, el dolor del mundo ${ }^{14}$.

No debe sorprender el que muchos se echen para atrás en un momento u otro de esta experiencia; se trata en verdad de una especie de enamoramiento. Ante la realidad ajena y cuestionante, uno siente que la tierra tiembla bajo los pies; se siente fuera de control, confundido, más pequeño y aun avergonzado; el horizonte de un mundo estrecho se abre a una realidad más rica y amplia. Así, el enamoramiento que hace temblar, alberga también riquezas insospechadas, se abre a niveles todavía más profundos. En este caso, los que se abandonan a la experiencia y se dejan llevar por ella lograrán percibir en los ojos del pobre (permitaseme la metáfora) algo que invita y atrae más allá de pobres particulares, algo trascendental e incomprensible. En presencia de este algo, la persona que se siente pequeña y cómplice comienza a sentirse paradojicamente acogida y aceptada en forma fundamental, aun antes de limpiar su expediente con el pobre. En el encuentro con él, uno se siente ante el Misterio Santo. Experimenta la gracia, a veces mediada por la misma acogida incondicional de pobres concretos.

En nuestra huida habitual del mal (la muerte y el pecado), jamás logramos escapar a la sospecha de que las cosas van mucho peor de lo que nos atrevemos a admitir. Pero el pobre nos echa el mal en la cara, nos pone delante el mal 
ajeno y el propio. Así confirma nuestra sospecha y nos libera del gran peso del autoengaño, medio consciente, que queremos mantener. Pero asI nos ayuda a descubrir que la realidad es también mucho mejor de lo que nos atreverfamos a admitir. Hacen posible reconocer la revolución de amor que Dios está realizando en el mundo. Ahí donde abunda el pecado, sobreabunda la gracia (Rom 5, 20).

Ignacio Ellacuría dijo una vez que le parecia que todo el mundo había puesto los ojos en Centroamérica, y especulaba que eso era asi porque en estos pueblos crucificados se hacía presente en forma muy real aquel morir y resucitar que es el drama íntimo de toda persona y de toda la humanidad. El encuentro con el pobre revela que para poder apreciar la buena noticia de que la vida es mucho más maravillosa de lo que jamás nos atreverlamos a pensar, tenemos que aceptar que la vida es también más horrible de lo que nos alreveŕamos a pensar. Para compartir la esperanza dc los pobres, hay que compartir —escuchar y asumirsu dolor. Para tener esperanza en el mundo de hoy, hay que dejar que la víctima rompa el corazón. lleve a que perdamos nuestro control y ofrezca la experiencia del Misterio Santo, presente en el sufrimiento del mundo. Uno no puede ver la obra de resurrección que se está realizando en el mundo si no es capaz de captar las crucifixiones que siguen aconteciendo. Precisamente en este drama concreto e histórico del misterio pascual encuentra uno a Dios.

Hemos dicho que el Resucilado se hace presente como quien otorga consuelo, alegría, generosidad, a pesar de todo. Los que visitan Centroamérica se topan con lo que san Ignacio de Loyola llama "consolacion sin causa precedente". Esta alegría y serenidad no viene de tener comodidades o buena salud, lo cual no posecn los pobres. Buscamos la causa y no la encontramos. Sólo Dios puede dar esta consolación sin causa ${ }^{15}$. Esto significa que Dios está presente entre esta gente en forma de Consolador de los afligidos, como fuente de alegría y esperanza y por tanto de lucha por un mundo nuevo, a veces contra toda esperanza. Y los pobres comunican esta esperanza precisamente a los que están dispuestos a compartir su dolor, dispuestos a escuchar sus historias y a caminar con ellos. Comunican a otros la misma consolación que han recibido de Dios $(2 \operatorname{Cor} 1,4)$.

Sin duda alguna, los no pobres necesilan a los pobres más que lo contrario. Allá en el norte, puede haber fe y amor, y sabemos que hay solidaridad. Pero lo que no se encuentra en el norte es la esperanza. En el tercer mundo, sin embargo, hay esperanza porque hay fe y hay proyecto en común en favor de la vida.

Pero a todo esto hay que añadir, como ya dijimos, que los no pobres no son los únicos que viven alejados de la realidad, aunque a los pobres, por sus propias condiciones de vida, les sea más diflcil huir de la realidad ${ }^{16}$. Existen, en efecto, pobres insolidarios que huyen de la realidad y de la responsabilidad, cayendo en sus "vicios", etc. De esa forma comparten, a su manera, la misma confusión que aflige a los no pobres. Por esto, paradójicamente, el caso extremo del encuentro del no pobre con el pobre puede servir como ejemplo ilustrativo 
de la problemática de todos ante el pobre. Aunque el contraste sea menor, el pobre también necesila asumir como propio el dolor del prójimo pobre. y así nos encontramos ante el Misterio de Dios.

\subsection{Implicaciones}

Se encuentra a Dios en las víctimas de la historia. Estas víclimas son como una puerta que se abre ante el misterio insondable del Dios trascendente. ¿Por qué? Porque este Dios toma partido por aquellos — sean "buenos" o "malos"cuyas vidas esı́́n amenazadas. Dios lucha contra la muerte: "He venido para que tengan vida y la tengan en abundancia" (Jn 10, 10). Dios se encuentra allá donde la vida está en juego (Mt 25, 31-46). La lucha por la vida en contra de la muerte y por la libertad contra la esclavitud es, en el fondo, la lucha enire la gracia y el pecado, entre el Dios de la vida y los ídolos de la muerte.

De acuerdo a la teología de la modernidad, Dios se comunica a la historia para transformarla. Se trata de un paradigma fundamentalmente tomista: Dios (gratia) transforma la historia (natura). La teología desde los pobres insiste, más bien, en colocar la bipolaridad Dios-historia (gracia-naturaleza) dentro del marco gracia-pecado, o Dios de vida versus ídolos de muerte. Afirma, con Pablo y Juan, que el pecado es precisamente aquello que esclaviza y lleva a la muerte, y que se encuentra a Dios de manera privilegiada allá donde la vida humana -en todas sus dimensiones y riqueza- es amenazada. Las luchas de liberación en favor de la vida (que rebasan con mucho el cambio meramente estructural) revelan muy especialmente el drama más profundo de la historia, porque en estas luchas se tocan los ídolos, especialmente la riqueza y el poder, que cobran vidas humanas, y éstos reaccionan con violencia como los demonios en los exorcismos de Jesús.

\subsection{La conversión}

En el encuentro con las víctimas, Dios se ofrece y acoge a la persona incondicionalmente, y, a la vez, invita a la conversión. Esto último signilica asumir la verdad de la experiencia e identificarse con el pobre. Implica una ruptura con el mundo dividido en personas importantes y personas sin importancia. Significa, por último, ruptura con "el hombre viejo".

Se trata de emprender un peregrinaje largo y diffcil de solidaridad, una aventura llena de posibles fracasos. Se trata de echar la suerte con los prójimos pobres. El pobre pone a la persona solidaria ante su propio miedo a la muene y a su pecado, y de esta forma le ayuda a vivir en y desde su propio centro. El solidario deja de huir del mal y de la muerte. Apuesta su vida, la arriesga, y, como dice Jesús, la encuentra (Mc 8, 35). El solidario se encarna más en la historia, y el pobre. Siervo de Yahvé. le sirve como lugar de encuentro con Dios en el corazón de la historia. 
Todo lo anterior amplia y explica la conocida tesis biblica: "Hacer justicia es conocer (encontrar) a Dios" (Jer 22, 16; cfr. Os 4, 1-2; 6, 4-6; Is 1, 3ss; 11, 9). "Todo el que ama ha nacido de Dios y conoce a Dios" (1 Juan 4, 7)". Si los mejores representantes de la teología moderna afirman la unidad experiencial del amor a Dios en el amor al projimo, la teologia desde los pobres insiste en que el "objeto" del amor es en primer lugar la víctima (como lo afirma la parábola del buen samaritano) y su objetivo es la liberación y la comunión. Insiste en que el amor del Nuevo Testamento realiza aquella justicia bíblica (sedeq, mishpat $y$ sedagah) que significa en primer lugar la liberación del pobre".

Digamos, para terminar, que la lucha diaria contra la muerte sigue siendo la experiencia "normal" de la raza humana. Pero los seres humanos solemos vivir algo desencarnados de esta realidad y descentrados con respecto ella. Huimos del pobre, de nosotros mismos y de Dios. Si bien la frágil conciencia modema se encuentra fácilmente ante el abismo, sin embargo - aunque todo es posible para Dios-, siguen siendo las víctimas de la historia las que nos ponen necesariamente ante el Misterio Santo que es el Dios de la vida.

\section{Nuestra respuesta}

\subsection{Fe-amor}

Dios se nos ofrece $y$, al acogernos, nos invita a corresponder a su oferta. Somos apertura a la autodonación de Dios ${ }^{19}$, y ella misma (la gracia) nos permite corresponderle de verdad. La respuesta abarca una dimensión de "fe" y otra dimensión de "amor".

En un primer momento, "fe" significa "dejarse llevar por la realidad", no resistir a la verdad de la experiencia. En última instancia, significa aceptar el que Dios nos acepia y, de hecho, aceptar a Dios. Significa aceptar ser perdonado, gratuitamente $-\mathrm{y}$ por tanto implica arrepentirse. Significa abandonar mi vida entera, mi destino entero al Misterio Santo (Deut 5,6). Significa no poner mi seguridad en cosa alguna, en nada. Significa actuar sin ldolos y, por tanto, sin temor y con libertad.

Este acto de abandono no es un vivir en pasividad. Dejarnos llevar por la experiencia de la víctima, por la verdad del morir-y-resucitar en la historia, significa asumir nuestra identidad con las victimas, amándolas como a nosotros mismos (Mt 7, 12; 22, 39).

Se trata de un amor "político" en sentido amplio. "Dios se ofrece" significa "Dios ofrece el reino", ya que la llegada del reino es teofanía. Aceptar el reino significa aceptar relaciones sociales nuevas, significa hacer justicia.

En otras palabras, Dios se hace presente en mi vida, por medio de circunstancias concretísimas, como la oferta (o la posibilidad) de vivir de una manera 
nueva - juntos. Experimento a Dios en mi vida diaria y concreta como la posibilidad real de vivir en comunidad. Aceptar la oferta es realizar esta posibilidad: amar al projimo y luchar por una comunidad nueva, el reino.

Nuestra respuesta, pues, se resume en el amor. La lucha por la vida, según el espiritu cristiano, no es lucha por la propia vida. Significa más bien estar dispuesto a dar la vida propia en servicio de la vida de los demás, especialmente de aquellos cuyas vidas están en peligro y culmina en la disponibilidad de dar la vida por el "enemigo". El buen samaritano se preocupó precisamente por una victima que era, al mismo tiempo, "enemigo" y no paisano.

\subsection{Unidos a Dios al buscar y cumplir su voluntad}

La persona que ama habilualmente vive unida a Dios, aunque no de manera necesariamente consciente. Ha sufrido un cambio radical, un cambio ontologico. $\mathrm{Ha}$ "nacido de nuevo", ha sido "bautizado en Cristo", es "creación nucva", "persona nueva", ha hecho una "opción fundamental". Para esla persona, aun con sus pecados e imperfecciones, cualquier acontecimiento o cualquier cosa -una flor, una mariposa- puede ser una mediación de la experiencia del Dios verdadero. Pcro para la persona que no ama, ninguna flor ni mariposa le puede poner ante el Dios de la vida. El que no ama no conoce a Dios (IJuan 4, 7). La persona que ama encuentra a Dios en todas las circunstancias y los detalles de la vida diaria ${ }^{20}$.

No nos unimos a Dios huyendo de la realidad. Todo lo contrario. Huir de la realidad es huir de Dios. Encontramos a Dios encarnándonos en la realidad y respondiendo al mundo, es decir, respondiendo al projimo. Esto no tiene nada que ver con un activismo sin contemplación. Todo lo contrario. La contemplación y la oración se imponen para la persona que quiere mantenerse en la rcalidad del mundo y de Dios-en-el-mundo, y que quiere resistir a los engaños e idolatrías del mundo y a la tentación permanente de huir de él.

Esta relación de amor con Dios nos lleva directamente a comunicarnos cada día con un Amigo muy querido. Sin embargo, comunicarse directamente con Dios, la oración, es sólo una manera, aunque también indispensable, de cstar unidos a Dios. Pero hay que estar claros en que no cs la contemplación-oración en sí la que nos une a Dios. Buscar y hacer su voluntad es lo que nos une a Dios. Si es la voluntad de Dios barrer las gradas o sacar la basura o preparar el almuerzo, ahí, en estas acciones, estaremos unidos a Dios, y no menos que en la Eucaristla. De lo contrario, deberíamos pasar todo el día anie el sagrario o allí donde pensamos estar más unidos a Dios. Y si en lugar de preparar el almuerzo cuando nos toca hacerlo, lo rehuimos y vamos a misa, no estamos en contacto con Dios.

Estamos unidos a Dios al buscar y hallar su volunlad, que consiste, en defi- 
nitiva, en amar. Esta voluntad de Dios no es algo oscuro y desconocido que hay que adivinar. La "voluntad de Dios", dice Pablo, es realizar en el mundo "lo bueno, lo correcto y lo acabado" (Rom 12,2) -todo ello a la luz de la realidad.

¿Podemos saber con certeza cuál es la concreta voluntad de Dios? Lo que Dios quiere es que busquemos sinceramente y que respondamos con libertad a la realidad, intentando maximizar el bien y minimizar el mal en el mundo. Podemos equivocarnos, pero Dios nos reafirma en la libertad, que nos lleva a cometer también ertores puntuales y a elegir con frecuencia sólo un bien menor. Estamos unidos a Dios cuando ejercemos la libertad necesaria para buscar en comunión con ouros, dentro de una Iglesia y con fidelidad creativa a la Palabra de Dios, cuál es su voluntad.

\section{Notas:}

1. Se trata en general de la conciencia de un mundo objetivo. No queremos acusar a la teologia moderna de presentar siempre la experiencia de Dios como algo puramente interior.

2. Karl Mannheim, Ideología y utopía: Introducción a la sociología del conocimiento, tr. Eloy Terron (Madrid 1993), capitulos 1 y 2.

3. Peter L. Berger y Thomas Luckmann, La construcción social de la realidad: Ensayo sobre la sociología del conocimienso, tr. Silvia Zuleta (Buenos Aires, 1972).

4. Cfr. Karl Rahner, "Gotteserfahnung Heute" en Schriffen zur Theologie, Band IX (Zürich/Koln 1990) 161-176. Para Rahner, la "existencia" como tal, y no el mundo (como antes), sirve hoy de mediacion de la experiencia de Dios, ibid. 173. Cfr. también Karl-Heinz Weger, "Ist Goll erfahsbar?", Stimmen der Zeit 210 (1992) 333-41; versión condensada en español: "¿Es posible la experiencia de Dios?", Selecciones de Teologia, vol. 32, No. 126 (1993) 165-171.

5. Dios ha arrinconado las aguas del caos, ha destruido los monstruos marinos: Gén 1, 2: Job 7,12; 9,13; 40,25ss; Sal 65,8; 74,13s; 77,17; 89,10s; etc.

6. Para loda esta sección, cfr. Karl Rahner, Curso fiundamental sobre la fe. Introducción al concepto de cristianismo (Barcelona 1984) 1-116; "Sobre el concepto de misterio en la teología católica", Escritos de teología, Tomo IV (Madrid 1961) 53-101; "Gotteserfahnung heute" (citado anteriomente en la nota 4).

7. Cfr. Rahner, Curso fundamensal, pp. 40-41.

8. No se trata meramente de la "inautenticidad" de la que hablan los existencialistas; se trata de las tinieblas de que habla el Evangelio de Juan. Es "el mundo", en sentido negativo, que comparto con otros. Ese mundo tiene expresiones sociales, políticas, ideológicas, etc., pero no tiene verdad.

9. Karl Rahner, "Sobre la unidad del amor a Dios y el amor al prójimo", Escritos de ieología, Tomo VI (Madrid 1969) pp. 271-292.

10. Jon Sobrino, Resurrección de la verdadera Iglesia: Los pobres, lugar teológico de la eclesiología (San Salvador 1986), capitulo 5, "La experiencia de Dios en la Iglesia de los pobres", especialmente pp. 163 y 166-67. Como el título sugiere, el artículo resalta el carácter comunilario y eclesial de la experiencia de Dios.

11. Pablo Richard (ed.), La lucha de los dioses (San José 1980); Jon Sobrino, Jesucristo liberador. Lectura historico teológica de Jesús de Nazaret (San Salvador 1991),

Digitalizado por Biblioteca "P. Florentino Idoate, S.J."

Universidad Centroamericana José Simeón Cañas 
"Excurso II. La cuestión de Dios: Dios de vida e ídolos de muerte".

12. Es una tentación para los no pobres preocuparse prematuramente por lo que ellos mismos pueden dar o hacer por los pobres. En todo caso, lo que los pobres más necesitan es que alguien los escuche. Es más fácil aguantar el hambre que el desprecio, que es el látigo más cruel de la pobreza y la opresión. Escurchar al pobre atentamente es respetarlo, pues los pobres sólo historias tienen. Pero esto es mucho, y escuchar estas historias es precisamente lo que el no pobre necesita para su propia liberación y salvación.

13. En la primera meditación sobre el pecado de sus Ejercicios Espirituales, san Ignacio señala que "lo que quiero y deseo" es "vergulenza y confusión de ml mismo". Ejercicios espirituales $\mathrm{N}^{0} 48$.

14. "Llamo consolación (...) asimismo cuando [el ánimo] lanza lágrimas motivas a amor de su Sef̃or, ahora sea por el dolor de sus pecados, o por la pasión de Cristo nuestro Sefior, o de otras derechamente ordenadas en su servicio o alabanza". Ejercicios esprisuales, $\mathrm{N}^{\circ}$ 316. Presuponemos aquí la identificación del pobre en su pasión con Cristo.

15. Ejercicios esprirituales Nn. 224 y 330 . Martín Maier S.J., muy cercano a K. Rahner en los últimos años de su vida, comunicó al autor que éste consideraba esta consolación como una experiencia de Dios sin mediación

16. Si bien no hay que idealizar a los pobres, tampoco hay que olvidar que supieron recibir el mensaje de Jesús más que otros $(\mathrm{Ml} 11,25)$. "La potencia obediencial del hombre para ser oyente de la palabra se concretiza como la potencia obediencial del pobre y empobrecido para oír esa palabra como Buena Nueva y así como palabra de Gracia", J. Sobrino, "La experiencia de Dios", pp. 158-59. No queda del todo obvio que esta apertura cortesponde a una virud moral del pobre. Bien puede responder a que la situación objeliva del pobre se presta menos a la huida del mensaje.

17. Cfr. Gustavo Gutiérez, Teología de la liberación. Perspectivas (Salamanca 1977) 251-254; José P. Miranda, Marx y la Biblia. Crífica filosofica de la opresión (Salamanca 1975) 67-77.

18. Dean Brackley, "Evolución del concepto de justicia con referencia al capitalismo y socialismo", Revista Latinoamericana de Teología 30 (1993) 265-67.

19. Somos una "alerta ontologica", escuchadores de la Palabra potentia oboedientialis.

20. Las paredes de algunas casas de retiro y de oración suelen cubrirse con cuadros de bellos paisajes, flores y mariposas. No tenemos nada en contra, con tal de que se incluyan también y en primer lugar los rostros de las victimas, primer sacramento de Dios. 